\title{
Lysophosphatidic acid receptor 4 signaling potentially modulates malignant behavior in human head and neck squamous cell carcinoma cells
}

\author{
SEN MATAYOSHI ${ }^{1,2}$, SHUNMEI CHIBA ${ }^{1}$, YANFUI LIN ${ }^{1}$, KAZUNARI ARAKAKI $^{1}$, HIROFUMI MATSUMOTO ${ }^{1}$, \\ TAKAYA NAKANISHI ${ }^{1}$, MIKIO SUZUKI ${ }^{2}$ and SEIYA KATO $^{1}$ \\ Departments of ${ }^{1}$ Pathology and Cell Biology and ${ }^{2}$ Otorhinolaryngology, Head and Neck Surgery, \\ Graduate School of Medicine, University of the Ryukyus, Nishihara, Okinawa 903-0215, Japan
}

Received December 6, 2012; Accepted February 8, 2013

DOI: $10.3892 /$ ijo.2013.1849

\begin{abstract}
Head and neck squamous cell carcinoma (HNSCC) is the sixth most common non-skin cancer worldwide. Despite improvement in therapeutic strategies, the prognosis of advanced HNSCC remains poor. The extacellular lipid mediators known as lysophosphatidic acids (LPAs) have been implicated in tumorigenesis of HNSCC. LPAs activate $\mathrm{G}$-protein-coupled receptors not only in the endothelial differentiation gene (Edg) family (LPA1, LPA2, LPA3) but also in the phylogenetically distant non-Edg family (LPA4, LPA5, LPA6). The distinct roles of these receptor isoforms in HNSCC tumorigenesis have not been clarified. In the present study, we investigated the effect of ectopic expression of LPA4 in SQ-20B, an HNSCC cell line, expressing a trivial level of endogenous LPA4. LPA (18:1) stimulated proliferation of SQ-20B cells, but did not affect proliferation of HEp-2, an SCC cell line expressing higher levels of LPA4, comparable to those of with LPA1. LPA-stimulated proliferation of SQ-20B cells was attenuated by Ki16425 and Rac1 inhibitor, but not by Y-27632. Infection with doxycycline-regulatable adenovirus vector expressing green fluorescent protein-tagged LPA4 (AdvLPA4G) abolished LPA-stimulated proliferation in SQ-20B cells with the accumulation of G2/M-phasic cells. Ectopic LPA4 induction further downregulated proliferation of Ki16425-treated SQ-20B cells, of which downregulation was partially recovered by LPA. Ectopic LPA4 induction also downregulated proliferation of Rac1 inhibitor-treated SQ-20B cells, however, LPA no longer recovered it. Finally, LPA-induced cell motility was suppressed by ectopic LPA4 expression as well as by Ki16425, Rac1 inhibitor or Y-27632.
\end{abstract}

Correspondence to: Dr Seiya Kato, Department of Pathology and Cell Biology, Graduate School of Medicine, University of the Ryukyus, 207 Uehara, Nishihara, Okinawa 903-0215, Japan E-mail: seikato@med.u-ryukyu.ac.jp

Key words: lysophosphatidic acid receptor 4, head and neck squamous cell carcinoma, Rac, Rho, adenovirus vector
Our data suggest that LPA4 signaling potentially modulates malignant behavior of SQ-20B cells. LPA signaling, which is mediated by both Edg and non-Edg receptors, may be a determinant of malignant behavior of HNSCC and could therefore be a promising therapeutic target.

\section{Introduction}

The annual incidence of head and neck squamous cell carcinoma (HNSCC), the sixth most common non-skin cancer in the world, is estimated to be $>600,000$ cases worldwide and the estimated number of deaths per year due to HNSCC is $\sim 350,000$ (1,2). Despite improvements in therapeutic strategies including surgery, radiotherapy and/or chemotherapy, the prognosis for patients with advanced-stage HNSCC remains poor, especially owing to loco-regional recurrence $(2,3)$. Tobacco use, alcohol consumption and human papilloma virus infection are recognized as major risk factors (2). Genetic mutation analysis data indicate that the mutational profile of HNSCC is generally consistent with those of other tumors with similar risk factors; in addition, $30 \%$ of cases harbor mutations in genes related to squamous differentiation (for example, NOTCH1, IRF6 and TP63) (4). The deregulation of specific signaling cascades such as epidermal growth factor receptor (EGFR), Ras and $\mathrm{Wnt} / \beta$-catenin signaling have also been reported in HNSCC tumorigenesis $(2,3,5)$. Although several molecular targeting regimens such as cetuximab (an EGFR inhibitor) and bevacizumab (a vascular endothelial growth factor receptor inhibitor) have been developed, their clinical trials have had limited efficacy and unexpected toxicities have been reported; these outcomes have emphasized the difficulties in controlling $\operatorname{HNSCC}(2,3)$. Further study is needed to understand the fundamental molecular basis of HNSCC tumorigenesis.

One molecule that has been implicated in HNSCC tumorigenesis is lysophosphatidic acid (LPA). LPAs are not only membrane phospholipid metabolates consisting of both saturated and unsaturated fatty acid chains but also extacellular lipid mediators that activate specific G-protein-coupled receptors (GPCRs). LPAs are ubiquitous bioactive molecules regulating various cellular events such as proliferation, migra- 
tion and anti-apoptotic effects in various kinds of cells; they are thus widely involved in development, homeostatic regulations and disease processes (6-8). LPAs are produced through the hydrolysis of lysophosphatidylcholine (LPC) by autotaxin (ATX), which was initially discovered as a tumor cell motility factor which exerts extracellular lysophospholipase D activity (6-9). LPA can be also produced through the hydrolysis of phosphatidic acid by soluble phospholipase A2 (6-8), but it has been shown using ATX heterozygous knockout mice that ATX is responsible for the bulk of LPA production in serum (10). Cancer cells of several types secrete large amounts of LPC, whereupon recombinant ATX stimulates proliferation and cell motility (9). In addition, overexpression of ATX has been reported in various malignant tumors such as small cell lung carcinoma, breast cancer and Hodgkin lymphoma (6-8). Upregulated LPA production by ATX in the cancer microenvironment has been implicated in malignant behavior of tumor cells. Thus, the ATX-LPA axis is thought to be a promising target for pharmacological intervention (6-8).

LPAs bind and activate GPCRs in the endothelial differentiation gene (Edg) family (LPA1/Edg2, LPA2/Edg4, LPA3/Edg7) as well as the phylogenetically distant non-Edg family (LPA4/p2y9/GPR23, LPA5/GPR92/GPR93, LPA6/ p2y5) (11-13). The Edg-family LPA receptors bind to LPAs in a similar manner and activate intracellular signaling pathways via $\mathrm{Gi}, \mathrm{Gq}$ and $\mathrm{G}_{12 / 13}$ proteins, which are supposed to be responsible for the major tumorigenic processes mediated by the ATX-LPA axis (11-13). The biological role of the more recently discovered non-Edg-family receptors is not yet fully understood. LPA4 (p2y9/GPR23) was identified through the ligand screening of orphan GPCRs sharing high amino acid sequence homology with the human platelet activating factor receptor, a known GPCR (14). LPA activates $\mathrm{G}_{12 / 13^{-}}$and Rho-mediated signaling in LPA4-expressing B103 neuroblastoma cells, which leads to neurite retraction and stress fiber formation $(15,16)$. LPA4 signaling also evokes intracellular cAMP accumulation via Gs activation and calcium ion mobilization via $\mathrm{Gq}$ and $\mathrm{Gi}$ activation $(15,16)$. Notably, Gs activation has not been reported downstream of the classic Edg-family LPA receptors (11-13,15,16). LPA4-deficient mice, such as LPA1- and LPA2-deficient mice, display no apparent phenotypic abnormalities, implicating the redundancy of signaling of LPA receptors (17). It has also been reported that LPA1- and LPA4-mediated signaling interact in the osteoblastic differentiation of human mesenchymal stem cells (18). LPA4 signaling also attenuates LPA1-mediated migration and invasion of B103 neuroblastoma and DLD1 colon cancer cells, suggesting functional antagonism between these two LPA receptors (17). Collectively, the expression profiles of LPA receptors and their downstream signalings are assumed to be related to malignant behavior of cancer cells, though this link has not been fully investigated.

It has been reported that LPA stimulates proliferation and motility in HNSCC cells (19). EGFR signaling has been shown to play a central role in HNSCC biology, which can be trans-activated by other receptor-mediated signaling cascades such as platelet-derived growth factor, insulin-like growth factor and LPA $(2,3,5,19)$. However, LPA also inhibits EGF-induced activation of signal transducer and activator of transcription 1 (STAT1) in A431 esophageal squamous cell carcinoma cells (20). Thus not all the effects of LPAs can be explained by trans-activation of EGFR. In the present study, we hypothesized that LPA signaling mediated by both Edg- and non-Edg receptor family members regulates malignant behavior of HNSCC cells. Overexpression of LPA4 was attempted in SQ-20B HNSCC cells, which natively express trivial levels of LPA4. LPAs, GPCR ligands that are abundantly present in the serum and body fluids, may play an important role in the establishment of the cancer microenvironment and in the regulation of malignant behavior of HNSCC (21).

\section{Materials and methods}

Cell culture and reagents. HEp-2, a human squamous cell carcinoma cell line, was obtained as previously described (22). The SQ-20B cell line of laryngeal squamous cell carcinoma was kindly provided by Professor Hideyuki J. Majima (Kagoshima University Graduate School of Medical and Dental Sciences) (23). Cells were maintained in Dulbecco's modified Eagle's medium (DMEM) (Sigma-Aldrich, St. Louis, MO) containing $10 \%$ fetal bovine serum (FBS) (Nichirei Bioscience, Tokyo, Japan) together with antibiotics $(100 \mathrm{U} / \mathrm{ml}$ penicillin and $100 \mu \mathrm{g} / \mathrm{ml}$ streptomycin; Life Technologies, Carlsbad, CA) at $37^{\circ} \mathrm{C}$ in a humidified atmosphere of $5 \% \mathrm{CO}_{2}$ and passaged with trypsin-EDTA (Life Technologies). LPA (oleoyl-1- $\alpha$-LPA, 18:1) and mouse monoclonal anti- $\beta$-actin antibody (AC-15) were purchased from Sigma-Aldrich, and the goat polyclonal anti-LPA4 antibody (S-15) from Santa Cruz Biotechnology (Santa Cruz, CA). Ki16425 was purchased from Cayman Chemical Co. (Ann Arbor, Michigan MI). Rac1 inhibitor and Y-27632 were purchased from Wako (Osaka, Japan), AG1478 from Merck (Darmstadt, Germany), and doxycycline (Dox) from Clontech (Mountain View, CA).

RNA extraction, conventional and real-time polymerase chain reaction $(P C R)$. Total RNA was isolated with TRIzol (Life Technologies) according to the manufacturer's instructions. Extracted RNA (1 $\mu \mathrm{g})$ was exposed to PrimeScript II reverse transcriptase (RT) (Takara, Otsu, Japan) in a total volume of $20 \mu \mathrm{l}$. For conventional RT-PCR, complimentary DNA obtained in $1 \mu \mathrm{l}$ of RT reaction mixture was amplified using AmpliTaq Gold PCR Master Mix (Applied Biosystems, Carlsbad, CA). PCR products were run and imaged on $1 \%$ agarose gels stained with ethidium bromide. For real-time PCR, $1 \mu \mathrm{l}$ of RT reaction mixture was amplified using Fast SYBR-Green fluorescence dye and a StepOne real-time PCR system (Applied Biosystems). Amplification reactions were performed in duplicate and fluorescence curves were analyzed with the included software. All PCR results were normalized for the expression of $\beta$-actin. Primers were designed using Primer 3 software (http://frodo.wi.mit.edu/ primer3/) running on a Windows computer. A primer set for $\beta$-actin (XAHR20 and XAHR17) purchased from Funakoshi (Tokyo, Japan) was used for conventional PCR. The PCR primer sets used in the present study and the experimental conditions are listed in Table I.

Assays for proliferation and cell motility. Viable cell numbers and proliferation rates were measured by means of WST-1 
Table I. Sequences of primers and experimental conditions for PCR.

A, Primers for the conventional PCR

Genes Sense primer

$\left(5-3^{\prime}\right)$

Antisense primer

Annealing

$\left(5-3^{\prime}\right)$

temperature $\left({ }^{\circ} \mathrm{C}\right)$

Amplified

size (bp)

\begin{tabular}{lllll}
\hline LPA1 & cgtgctggcctatgagaaat & tgtgaactccagccaagatg & 60 & 209 \\
LPA2 & ctgctcetggatggtttagg & tgggcagaggatgtatagtgg & 60 & 209 \\
LPA3 & ggacacccatgaagctaat & tctgggttctcctgagagaa & 60 & 256 \\
LPA4 & ctcttcgcaagcctgctact & gttcagagttgcaaggcaca & 60 & 221 \\
LPA5 & tctccegtgtcctgactacc & gccgtacatgttcatctgga & 60 & 286 \\
LPA6 & cagaagccacatggaaaaca & tgctgccactactgagcaat & 60 & 287 \\
$\beta$-actin & acccacactgtgcccatcta & cggaaccgctcattgcc & 60 & 289 \\
& (XAHR20 primer) & (XAHR17 primer) & 60 & \\
\hline
\end{tabular}

B, Primers for the real-time PCR

\begin{tabular}{lllll} 
Genes & \multicolumn{1}{c}{$\begin{array}{c}\text { Sense primer } \\
\left(5-3^{\prime}\right)\end{array}$} & \multicolumn{1}{c}{$\begin{array}{c}\text { Antisense primer } \\
\left(5-3^{\prime}\right)\end{array}$} & $\begin{array}{c}\text { Annealing } \\
\text { temperature }\left({ }^{\circ} \mathrm{C}\right)\end{array}$ & $\begin{array}{c}\text { Amplified } \\
\text { size }(\mathrm{bp})\end{array}$ \\
\hline LPA1 & tgcttggggcetttatcatc & ttctcataggccagcacgtc & 60 & 94 \\
LPA2 & atcatcctgggggcgttc & cattgcaggactcacagccta & 60 & 85 \\
LPA3 & taggggcgtttgtggtatgc & cacctttcacatgctgcac & 60 & 97 \\
LPA4 & ccatgggtgacagaagattca & ggcagtagcattgcccaac & 60 & 83 \\
LPA5 & tctctgctgctgatgaagctg & agggaggtcatgggaatgtg & 60 & 92 \\
LPA6 & ccagcggaaatttacagca & gcaaattatctggatcttggatg & 60 & 99 \\
$\beta$-actin & atccgcaagacctgtacgc & ccagggcagtgatctccttc & 60 & 97 \\
\hline
\end{tabular}

[2-(4-iodophenyl)-3-(4-nitrophenyl)-5-(2,4-disulfophenyl)-2Htetrazolium, a tetrazolim salt], assay (Roche, Indianapolis, IN) according to the manufacturer's instructions. Briefly, cells were inoculated on a 96-well multi-titer plate at a density of $5 \times 10^{3}$ cells per well. To equilibrate the cell cycle phase, the cells were cultured in serum-free media (SFM) prior to LPA stimulation. The plates were read at wavelength of $450 \mathrm{~nm}$ using a scanning multi-well spectrophotometer (Bio-Rad, Model 680, Hercules, CA). For the measurement of cell motility, a wound-healing assay was performed (24). Briefly, cells were seeded on each side of an Ibidi culture insert for live cell analysis (Ibidi, Munich, Germany) and the area filled with migrated cells was observed using an Olympus phasecontrast microscope (model CKX41, Tokyo, Japan) connected to a DP50 digital camera (Olympus). Image analysis was performed using Image $\mathbf{J}$ software (NIH, Bethesda, MD).

Cell cycle analysis. For flow cytometric analysis of the cellcycle distribution, cells were harvested using trypsin-EDTA and fixed with $70 \%$ ethanol. Fixed cells $\left(1 \times 10^{5}\right)$ were stained with $200 \mu \mathrm{l}$ of Guava cell cycle reagent (Millipore, Billerica, MA) and analyzed using the Guava Personal Cell Analysis System (Millipore) according to the manufacturer's instructions.

Recombinant adenovirus vector. Full-length cDNA of human LPA4 with C-terminal turbo green fluorescence protein (tGFP) tag (Origene, Rockville, MD) was subcloned into the recombinant adenovirus vector (AdvLPA4G) using an Adeno-X
Tet-On 3G system (Clontech) according to the manufacturer's instructions. AD293 cells (Agilent Technologies, Santa Clara, CA) were used as a packaging cell line and a ViraBind ${ }^{\mathrm{TM}}$ adenovirus purification kit (Cell Biolabs, San Diego, CA) was used for amplification. Working stocks of viruses were stored in aliquots at $-80^{\circ} \mathrm{C}$. Titer was determined by means of a conventional plaque assay using Noble Agar (Difco, Detroit, MI). Dox-negative condition was used as a negative control. Transfection efficiencies were tested with GFP fluorescence as observed with an Olympus fluorescent microscope.

Western blotting. Whole cell extracts were obtained in RIPA buffer (Santa Cruz Biotechnology) and were then subjected to the Quick Start Bradford Protein Assay kit (Bio-Rad). Whole cell extracts $(30 \mu \mathrm{g})$ were subsequently resolved in $10 \%$ sodium dodecyl sulfate (SDS)-polyacrylamide gel electrophoresis (PAGE) and were electronically transferred to a nitrocellulose membrane (Bio-Rad). The membranes were probed with a 1:200 dilution of a goat polyclonal anti-LPA4 followed by incubation with a 1:5000 dilution of peroxidase-conjugated secondary antibody-like particle (supplied in an XL-SAP kit for western blotting, APRO Life Science, Naruto, Japan). The proteins were subsequently developed using ImmunoStar LD reagents (Wako) and visualized with a luminescent imager (Ez-Capture, ATTO Co., Tokyo, Japan). Alternatively, the blots were incubated with Restore PLUS Western Blot Stripping Buffer (Thermo Fisher Scientific, Waltham, MA) and re-probed with a 1:2000 dilution of anti- $\beta$-actin antibody. 
A

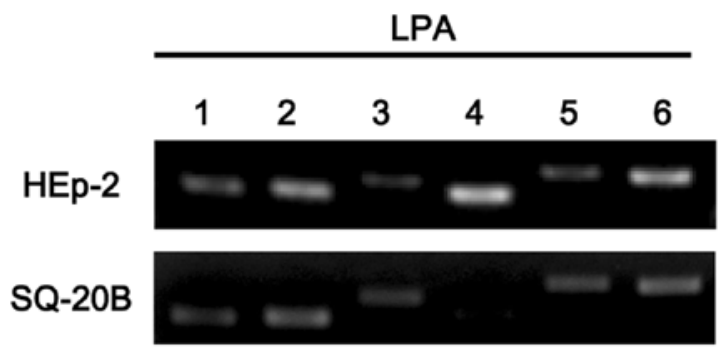

B

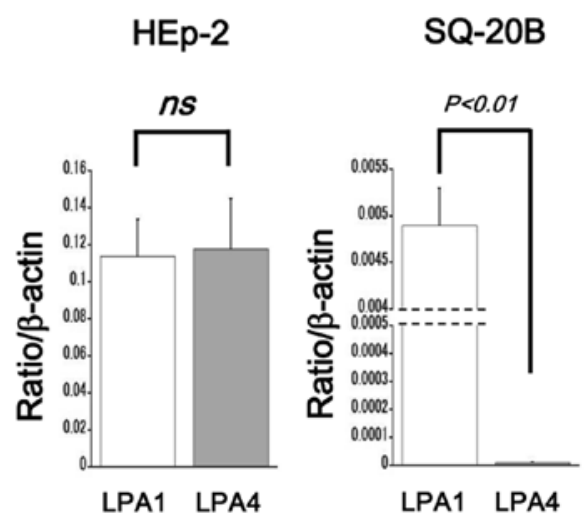

Figure 1. Expression profile of LPA receptors in HEp-2 and SQ-20B cells. (A) Conventional RT-PCR for LPA1-6. (B) Real-time PCR for LPA1 (open bars) and LPA4 (gray bars). Data are shown as the mean \pm SEM $(n=3)$. $\mathrm{P}$-values are indicated; ns, not significant.

Statistical analysis. Experimental groups were compared using analysis of variance (ANOVA) and, when appropriate, Student's $t$-test. The data are expressed as the mean \pm SEM. A level of $p<0.05$ was considered statistically significant.

\section{Results}

Expression of LPA1 and LPA4 in human squamous cell carcinoma cells. The expression profiles of LPA receptors in various cancer cell types were screened with conventional RT-PCR. HEp-2 cells expressed all isoforms of LPA receptors (LPA1-6, Fig. 1A, upper panel). SQ-20B cells expressed all Edg family LPA receptors (LPA1-3) and 2 isoforms of the non-Edg-family LPA receptors (LPA5 and LPA6). Slight expression of LPA4 was detected in SQ-20B cells (Fig. 1A, bottom panel). Realtime PCR revealed that expression levels of LPA1 and LPA4 were similar in HEp-2 cells, while only a trivial level of LPA4 expression was seen in SQ-20B cells (Fig. 1B).

LPA stimulated proliferation in $S Q-20 B$ cells but not in HEp-2 cells. In HEp-2 cells, WST-1 assay revealed no mitogenic response against LPA. In SQ-20B cells, on the other hand, LPA stimulated proliferation in a dose-dependent fashion (Fig. 2A). Thus, further experiments were performed using LPA-responsive SQ-20B cells. Since it has been reported that LPA-induced mitogenic response largely depends on the transactivation of EGFR in some HNSCC cell lines (19), we tested the effect of AG1478, a specific inhibitor for EGFR. In the absence of LPA, AG1478 reduced proliferation of SQ-20B
A

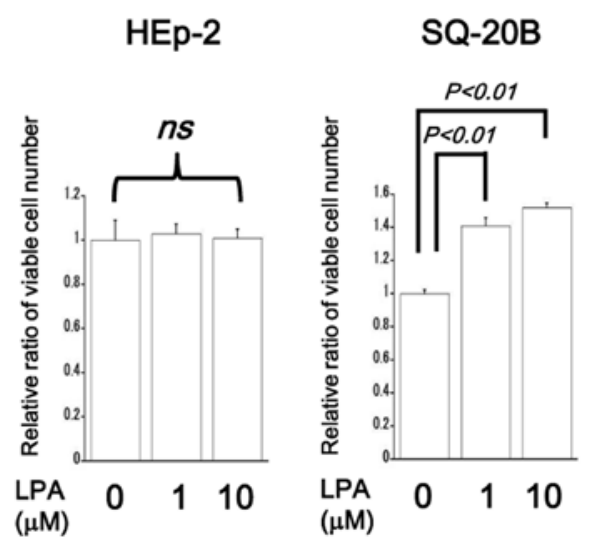

B

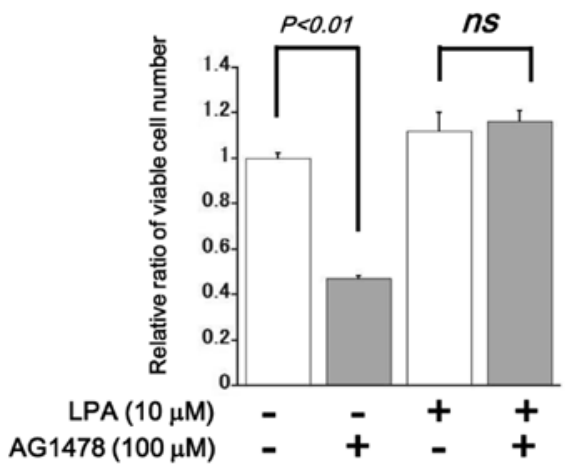

Figure 2. Proliferation assay of LPA-stimulated HEp-2 and SQ-20B cells. (A) Cells were starved with SFM for $24 \mathrm{~h}$. WST-1 assay was performed $48 \mathrm{~h}$ after the LPA stimulation (concentrations are indicated). (B) SQ-20B cells were stimulated with LPA $(10 \mu \mathrm{M})$ with (gray bars) or without (open bars) AG1478 treatment. AG1478 $(100 \mu \mathrm{M})$ was added 30 min prior to LPA stimulation. WST-1 assay was performed as above. Data are shown as the mean \pm SEM $(n=6)$. P-values are indicated; $n s$, not significant .

cells, suggesting the endogenous activation of EGFR in this cell line. In the presence of LPA, however, treatment with AG1478 did not result in reduced proliferation of SQ-20B cells, suggesting that LPA signaling stimulates proliferation of SQ-20B cells independently from EGFR activation (Fig. 2B).

LPA stimulated proliferation of $S Q-20 B$ cells via the activation of Kil6425-sensitive Edg family receptors and Racl. To investigate the intracellular signaling mechanism responsible for LPA-stimulated proliferation in SQ-20B cells, the effects of the LPA1 and LPA3 inhibitor Ki16425 $(10 \mu \mathrm{M})$, Rac1 inhibitor $(50 \mu \mathrm{M})$ and the Rho-associated coiled-coil forming kinase (ROCK) inhibitor Y-27632 $(10 \mu \mathrm{M})$ were tested (25). Treatment with Ki16425 or a Rac1 inhibitor inhibited proliferation of LPA $(10 \mu \mathrm{M})$-stimulated SQ-20B cell growth, whereas, treatment with Y-27632 showed no significant effect on proliferation in these cells (Fig. 3).

Overexpression of LPA4 in $S Q-20 B$ cells. Next, we attempted overexpression of LPA4 in SQ-20B cells which indigenously exhibit a trivial level of LPA4 expression (Fig. 1). A fluorescent image showed that AdvLPA4G (100 MOI, multiplicity of infec- 


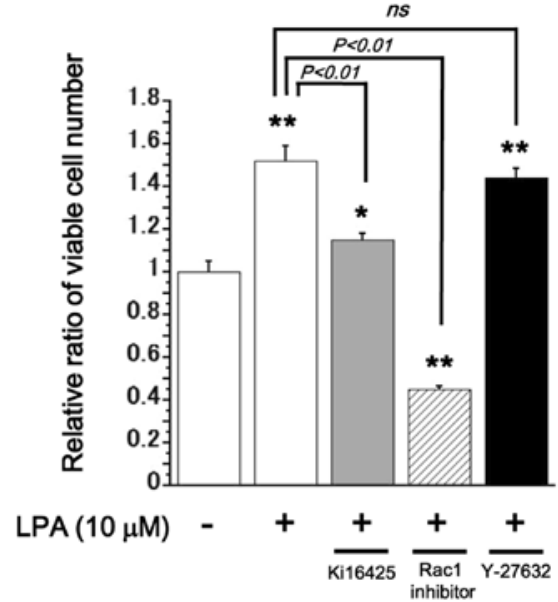

Figure 3. Proliferation assay of LPA-stimulated SQ-20B cells. Cells were starved with SFM for $24 \mathrm{~h}$. WST-1 assay was performed $48 \mathrm{~h}$ after the LPA stimulation $(10 \mu \mathrm{M})$ with or without (open bars) treatment with the inhibitors. Ki16425 (gray bar, $10 \mu \mathrm{M}$ ), Rac1 inhibitor (hatched bar, $50 \mu \mathrm{M}$ ), or Y-27632 (filled bar, $10 \mu \mathrm{M}$ ) was added $30 \mathrm{~min}$ prior to LPA stimulation. Data are shown as the mean \pm SEM $(n=6) .{ }^{*} \mathrm{P}<0.05 ;{ }^{* *} \mathrm{P}<0.01$ against the control LPAunstimulated cells. P-values are indicated; ns, not significant.

\section{A}

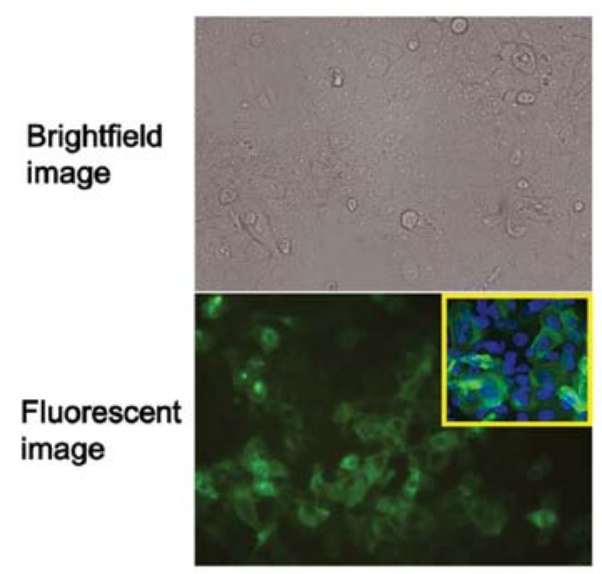

B

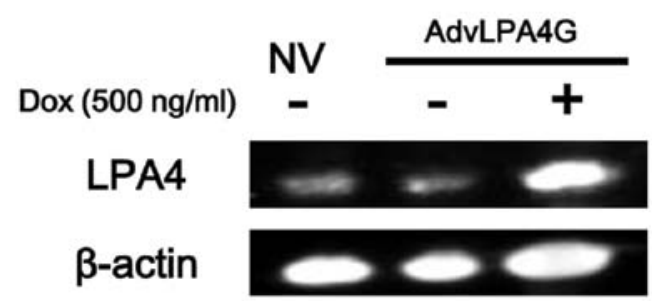

Figure 4. Ectopic expression of GFP-tagged LPA4 in SQ-20B cells (A) Observation by phase-contrast microscopy (inset; high magnification) SQ-20B cells were infected with $100 \mathrm{MOI}$ of AdvLPA4G. Ectopic expression of GFP-tagged LPA4 was observed $48 \mathrm{~h}$ after infection with Dox treatment $(500 \mathrm{ng} / \mathrm{ml})$. (B) Western blotting for LPA4 and $\beta$-actin. SQ-20B cells were infected with $100 \mathrm{MOI}$ of AdvLPA4G and were then incubated with $500 \mathrm{ng} /$ $\mathrm{ml}$ of Dox. Cell lysates were harvested $48 \mathrm{~h}$ after infection. $\mathrm{NV}$, no virus infected control cells.

tion) infected cells represented membranous and cytoplasmic expression of GFP-associated LPA4 protein in the presence of Dox (100-500 ng/ml of concentration was used in the present

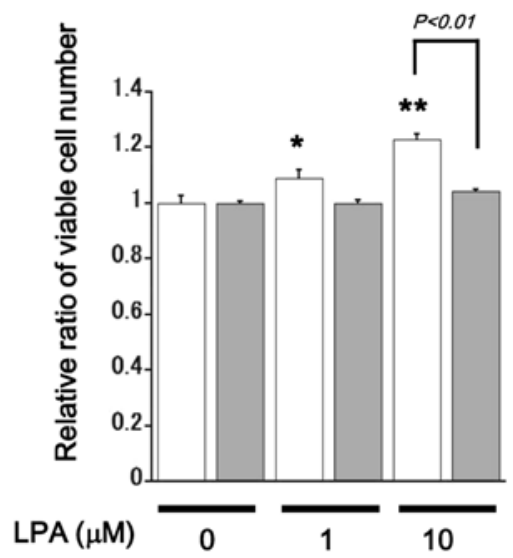

Figure 5. Proliferation assay of AdvLPA4G-infected SQ-20B cells. Cells were infected with $100 \mathrm{MOI}$ of AdvLPA4G and were then incubated for $24 \mathrm{~h}$ with (gray bars) or without (open bars) $100 \mathrm{ng} / \mathrm{ml}$ of Dox in SFM. WST-1 assay was performed $48 \mathrm{~h}$ after the LPA stimulation (concentrations are indicated). Data are shown as the mean \pm SEM $(n=6) .{ }^{*} \mathrm{P}<0.05 ;{ }^{* *} \mathrm{P}<0.01$ against the control unstimulated cells. P-values are indicated; ns, not significant.

Table II. Flow cytometric cell cycle analysis.

\begin{tabular}{lccc}
\hline & G0/G1 & S & G2/M \\
\hline Dox(-) control & $52.8 \pm 1.14$ & $11.4 \pm 0.33$ & $35.6 \pm 0.78$ \\
$\operatorname{Dox}(+)$ & $38.2 \pm 0.44^{\mathrm{a}}$ & $9.83 \pm 0.15^{\mathrm{a}}$ & $51.9 \pm 0.22^{\mathrm{a}}$
\end{tabular}

SQ-20B cells were starved in SFM for $24 \mathrm{~h}$ and flow cytometric cell cycle analysis was performed $6 \mathrm{~h}$ after LPA $(10 \mu \mathrm{M})$ stimulation. Percentages of cells in each cell cycle phase are shown as mean \pm SEM. ${ }^{\text {a }}<0.01$ against the controls.

study) (Fig. 4A). Western blot analysis also showed upregulated expression of LPA4 in Dox-treated AdvLPA4G-infected cells (Fig. 4B).

Overexpression of LPA4 inhibited LPA-induced mitogenic response in $S Q-20 B$ cells. LPA induced a mitogenic response in SQ-20B cells in the Dox-free control condition; this is consistent with the result shown in Fig. 2A. In ectopic LPA4expressing cells, in contrast, LPA-induced mitogenic response was completely inhibited (Fig. 5). In the presence of Ki16425, proliferation of SQ-20B cells was attenuated by the induction of ectopic LPA4 but could be partially rescued by the addition of LPA (Fig. 6A). In the presence of Rac1 inhibitor, proliferation of SQ-20B cells was suppressed irrespective of LPA treatment and no further reduction resulted from ectopic LPA4 induction (Fig. 6B). In the presence of Y-27632, no significant change in proliferation of SQ-20B cells was observed upon LPA treatment or ectopic LPA4 induction (Fig. 6C). Flow cytometric cell cycle analysis showed that the percentage of G2/M-phasic cells was increased $6 \mathrm{~h}$ after LPA stimulation in ectopic LPA4-expressing SQ-20B cells (Table II).

Inhibition of cell motility in LPA4-expressing $S Q-20 B$ cells. Cell motility was measured through a wound healing assay. 


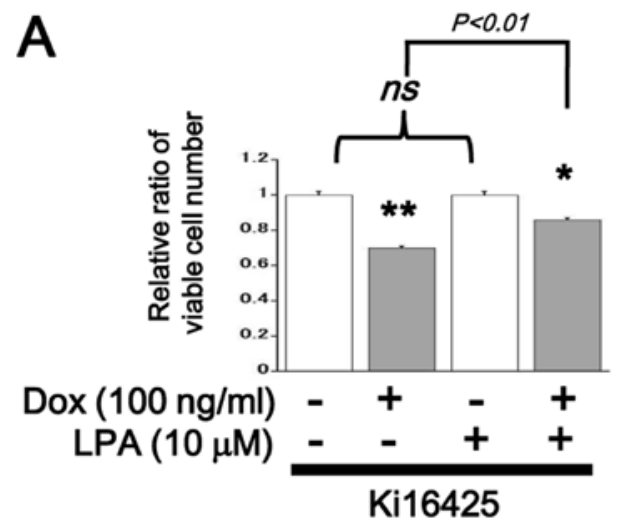

B

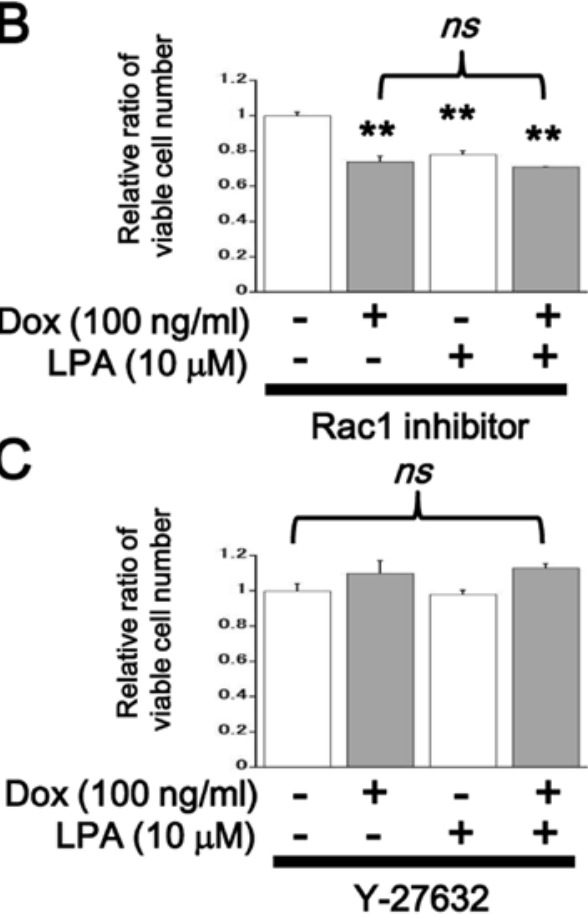

Figure 6. Proliferation assay of AdvLPA4G-infected SQ-20B cells in the presence of inhibitors. Cells were infected with 100 MOI of AdvLPA4G and were then incubated for $24 \mathrm{~h}$ with (gray bars) or without (open bars) $100 \mathrm{ng}$ / $\mathrm{ml}$ of Dox in SFM. WST-1 assay was performed $48 \mathrm{~h}$ after the LPA stimulation $(10 \mu \mathrm{M})$. Ki16425 [(A) $10 \mu \mathrm{M}$ ], Rac1 inhibitor [(B) $50 \mu \mathrm{M}]$, or Y-27632 [(C) $10 \mu \mathrm{M}]$ was added 30 min prior to LPA stimulation. Data are shown as the mean \pm SEM $(n=6) .{ }^{*} \mathrm{P}<0.05 ;{ }^{* *} \mathrm{P}<0.01$ against the control unstimulated cells. P-values are indicated; ns, not significant.

LPA upregulated cell motility in SQ-20B cells, while additional treatment with Ki16425, Rac1 inhibitor or Y-27632, suppressed it. Ectopic induction of LPA4 also reduced cell motility regardless of the presence or absence of inhibitors (Fig. 7).

\section{Discussion}

In the present study, we demonstrated that adenovirusmediated ectopic induction of LPA4 signaling potentially modulates malignant behavior of SQ-20B, HNSCC cells including proliferation (Figs. 5 and 6 ) and cellular motility (Fig. 7). Activation of Ki16425-sensitive Edg receptrors (LPA1 and LPA3) and Rac1 was identified as an important mitogenic cascade with which LPA4 signaling may interfere
(Figs. 3 and 6). Signaling mediated by both Edg and non-Edg receptors may be a determinant of malignant behavior of HNSCC and may therefore be a promising therapeutic target.

It is known that Edg-family LPA receptors (LPA1, LPA2, LPA3) have a ubiquitous distribution in most tissues. Non-Edg LPA receptors, on the other hand, appear to have low expression levels in many tissues (11-13). Exceptionally, high levels of LPA4 expression have been observed in the ovaries (11-14) and LPA5 expression has been identified in the small intestine, spleen and dorsal root ganglion cells $(11-13,26)$. LPA6 expression has been shown in the hair follicles and vascular endothelium $(11,27)$. In various other types of cells and tissues, however, the expression profiles of LPA receptors have not been investigated in detail. Here, we found that LPA4 was expressed at different levels in two different SCC cell lines, HEp-2 and SQ-20B (Fig. 1). More importantly, LPA stimulated proliferation only in SQ-20B cells, which exhibit trivial levels of LPA4 expression (Fig. 2). In our preliminary experiments, Detroit-562, another HNSCC cell line and HCT116, a colorectal cancer cell line, showed mild mitogenic responses against LPA in accordance with low levels of LPA4 expression (data not shown).

It was also previously reported that LPA-induced malignant behavior of cancer cells are largely dependent on Edg-family receptor activation $(6-8,11-13,21)$. Consistently, we observed the inhibition of LPA-induced mitogenic response in SQ-20B cells by Ki16425, an inhibitor for LPA1 and LPA3 (Fig. 3). On the contrary, LPA4, a non-Edg LPA receptor, potentially acts as a negative regulator for certain cellular events mediated by Edg-family receptors: for example, during osteoblast differentiation, LPA1 and LPA4 have been shown to exert distinct functions (18). Unfortunately, no specific inhibitor for LPA4 is available to date (12), but the development of one would be highly beneficial for shedding light on the role of LPA4 in physiological and disease processes.

Rho-family GTPases including Rho, Rac and Cdc42 are presumed to modulate various cellular functions such as cytoskeletal reorganization, cell motility, invasion, proliferation and apoptotic processes $(28,29)$. Rho-family GTPases are also major intracellular signaling molecules downstream of GPCRs including the LPA receptors (11-13). The mitogenic effect of LPA on SQ-20B cells was attenuated by Ki16425 and Rac1 inhibitor. Thus, the Gi-Rac signaling axis may play a role in LPA-induced proliferation downstream of Ki16425-sensitive Edg receptors (LPA1 and LPA3) (11-13). Y-27632, a Rho/ROCK inhibitor, had no significant effect on the proliferation of LPA-stimulated SQ-20B cells (Fig. 3). Among known LPA receptors, LPA4 has been shown to bind only to $\mathrm{G}_{12 / 13}$ proteins and to activate Rho (11-13). However, the $G_{12 / 13}$-Rho/ROCK pathway is not expected to be involved in the regulation of proliferation in LPA-stimulated SQ-20B cells.

Ectopic induction of LPA4 abolished LPA-induced mitogenic response in SQ-20B cells (Fig. 5), suggesting that LPA4 signaling acts as a negative regulator for proliferation. In the presence of Ki16425, LPA mildly recovered cell proliferation of ectopic LPA4 expressing SQ-20B cells (Fig. 6A), probably due to partial release from competitive inhibition by Ki16425 against LPA1 and LPA3 (30). In the presence of Rac1 inhibitor, ectopic expression of LPA4 no longer suppressed 
A

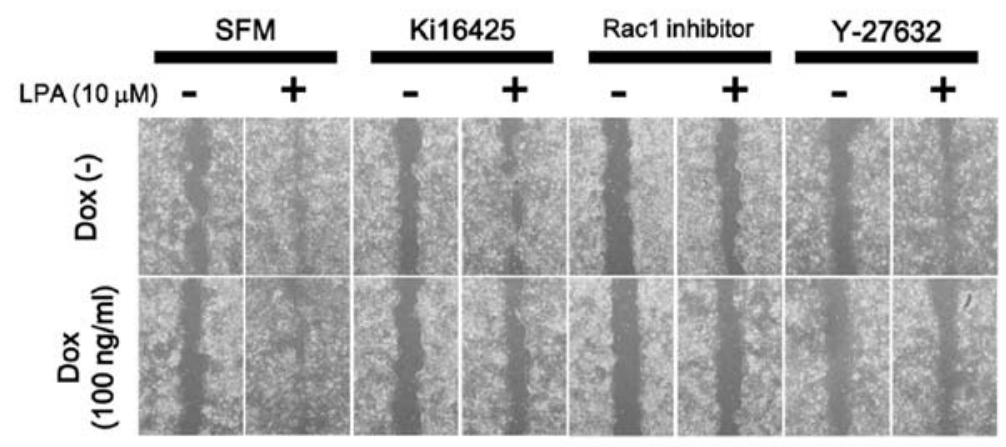

B

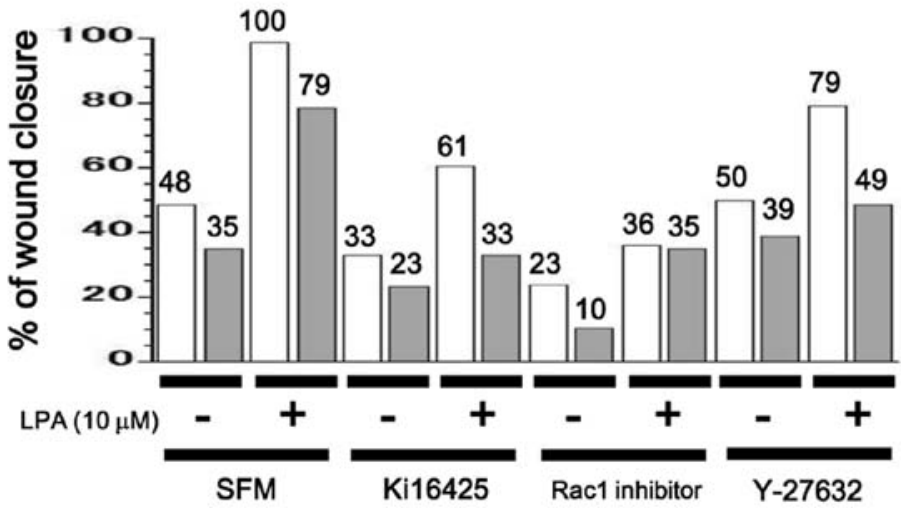

Figure 7. Wound healing assay of AdvLPA4G-infected SQ-20B cells. Cells were infected with 100 MOI of AdvLPA4G and incubated with [(A) lower panels; (B) gray bars] or without [(A) upper panels; (B) open bars] $100 \mathrm{ng} / \mathrm{ml}$ of Dox overnight followed by re-seeding on Ibidi culture inserts. Cells were pretreated with or without the inhibitors (Ki16425, $10 \mu \mathrm{M}$; Rac1 inhibitor, $50 \mu \mathrm{M}$; or Y-27632, $10 \mu \mathrm{M}$ ) before removal of the insert and then stimulated with LPA (10 $\mu \mathrm{M}$ ) for $8 \mathrm{~h}$. Percentage of wound closure (maximum 100\%) in each condition was measured as described in Materials and methods (values are also indicated at the top of individual bars). Representative data of two independent experiments are shown. (A) Phase-contrast microscope images. (B) Percentage of wound closure in each condition.

proliferation of SQ-20B cells (Fig. 6B). We also observed inhibition of LPA-induced Rac1 activation in ectopic LPA4 expressing SQ-20B cells using a pull-down assay (data not shown). Thus, LPA4 signaling may interfere with Rac1 activation in LPA-stimulated SQ-20B cells.

In our flow cytometric analysis, LPA-stimulated SQ-20B cells showed an accumulation of G2/M-phasic cells with an ectopic induction of LPA4 (Table II). Similarly, Rat-2, a rat fibroblast cell line, expressing dominant negative Rac1 (N17rac1) has been shown consistently to exhibit growth arrest at the G2/M phase (31). In the presence of Y-27632, a Rho/ROCK inhibitor, no significant changes were seen in the proliferation of SQ-20B cells irrespective of LPA4 induction (Fig. 6C). In various systems, it has been indicated that the activities of Rac and Rho may be antagonistic through their regulation of GEF (guanine nucleotide exchange factors, which act as activators) and GAP (GTPase-activating proteins, which act as inhibitors) (29,32-34). In the present study, however, we could not confirm the involvement of the $\mathrm{G}_{12 / 13}$-Rho/ROCK pathway in the regulation of SQ-20B cell proliferation downstream of LPA4. Further study is needed to identify the LPA4-mediated inhibitory pathway involved in the LPA-induced and Gi/Rac-mediated mitogenic response in these cells.
LPA stimulates not only proliferation but also cell motility in HNSCC cells $(19,35,36)$. Therefore, we examined the role of LPA4 signaling on cell motility in SQ-20B cells. Our wound healing assay data suggested that LPA-induced cell motility is mediated by Ki16425-sensitive Edg family receptor activation and the exogenously induced LPA4 signaling negatively regulates cell motility in SQ-20B cells (Fig. 7). Given that the inhibitor for either Racl or Rho/ROCK attenuated cell motility, these small G-proteins must play an important role in promoting cell motility in these cells. Rho proteins induce stress fiber and focal adhesion contact formation, whereas Rac and $\mathrm{Cdc} 42$ are involved in the formation of lamellipodia and filopodia $(28,29,32-34)$. Irrespective of any antagonistic relationship between the Rac and Rho/ROCK pathways (32-34), these small G-proteins would coordinately promote changes in cell motility (37). It has been reported that cell motility induced by LPA is associated with activation of RhoA and inhibition of Akt and Rac in embryonic fibroblasts derived from LPA4-deficient mice (17). It has also been reported that ATX promotes invasion in HT1080, fibrosarcoma cells via the activation of cyclic AMP/EPAC (exchange protein directly activated by the cyclic AMP)/Rac1 pathway at the downstream of LPA4 (38). Our data suggest that LPA4 signaling negatively modulates cell motility in HNSCC. The regulatory mechanism 
involved in this process, including the Rac and Rho/ROCK pathways, should be clarified in further investigations.

Known LPA receptors (LPA1-6) have been shown to mediate major cellular events through their effects on LPAs, though some LPA-mediated cellular functions may be mediated by the intracellular signaling molecule peroxisome proliferator-activated receptor (PPAR $\gamma)(39,40)$. Moreover, 2,3-cyclic phosphatidic acid, an endogenously produced PPAR $\gamma$ antagonist, that is similar in structure to LPA, inhibits cancer cell invasion and metastasis in vitro and in vivo (41). In IMR-32 human neuroblastoma cells, however, LPA antagonizes 15-deoxy- $\Delta 12$,14-prostaglandin J2-mediated PPAR $\gamma$ activation (42). Although we did not test the activation level of PPAR $\gamma$ in LPA-stimulated SQ-20B cells, the possibility of an interaction between trans-membrane LPA receptors and the intracellular targets of LPA in HNSCC needs to be addressed in a future study.

\section{Acknowledgements}

We would like to thank Professor Hideyuki J. Majima (Department of Oncology and Department of Space Environmental Medicine, Kagoshima University Graduate School of Medical and Dental Sciences), for the generous gift of the SQ-20B laryngeal squamous cell carcinoma cell line. We would like to thank Professor Satoshi Ishii (Department of Immunology, Graduate School of Medicine, Akita University), for helpful discussions and suggestions. We also gratefully acknowledge the technical assistance of Ms. Junko Shiroma (Department of Pathology and Cell Biology, Graduate School of Medicine, University of the Ryukyus). This study was supported in part by a Grantin-Aid for Scientific Research (C) to S.K. (no. 24590462) and a Grant-in-Aid for Young Scientists (B) to S.M. (no. 24791792) from the Ministry of Education, Culture, Sports, Science and Technology (MEXT), Japan. This work was also supported in part by Grants for the Project of Young Investigator Research (2010 and 2011) to S.C. from the University of Ryukyus.

\section{References}

1. Ferlay J, Shin HR, Bray F, Forman D, Mathers C and Parkin DM Estimates of worldwide burden of cancer in 2008: GLOBOCAN 2008. Int J Cancer 127: 2893-2917, 2010.

2. Argiris A, Karamouzis MV, Raben D and Ferris RL: Head and neck cancer. Lancet 371: 1695-1709, 2008.

3. Matta A and Ralhan R: Overview of current and future biologically based targeted therapies in head and neck squamous cell carcinoma. Head Neck Oncol 1: 6, 2009.

4. Stransky N, Egloff AM, Tward AD, Kostic AD, Cibulskis K, Sivachenko A, Kryukov GV, Lawrence MS, Sougnez C, McKenna A, Shefler E, Ramos AH, Stojanov P, Carter SL, Voet D, Cortés ML, Auclair D, Berger MF, Saksena G, Guiducci C, Onofrio RC, Parkin M, Romkes M, Weissfeld JL, Seethala RR, Wang L, Rangel-Escareño C, Fernandez-Lopez JC, Hidalgo-Miranda A, Melendez-Zajgla J, Winckler W, Ardlie K, Gabriel SB, Meyerson M, Lander ES, Getz G, Golub TR, Garraway LA and Grandis JR: The mutational landscape of head and neck squamous cell carcinoma. Science 333: 1157-1160, 2011.

5. Molinolo AA, Amornphimoltham P, Squarize $\mathrm{CH}$, Castilho RM, Patel V and Gutkind JS: Dysregulated molecular networks in head and neck carcinogenesis. Oral Oncol 45: 324-334, 2009.

6. Gendaszewska-Darmach E: Lysophosphatidic acids, cyclic phosphatidic acids and autotaxin as promising targets in therapies of cancer and other diseases. Acta Biochim Pol 55: 227-240, 2008.

7. Mills GB and Moolenaar WH: The emerging role of lysophosphatidic acid in cancer. Nat Rev Cancer 3: 582-591, 2003.
8. Moolenaar WH: Lysophospholipids in the limelight: autotaxin takes center stage. J Cell Biol 158: 197-199, 2002.

9. Umezu-Goto M, Kishi Y, Taira A, Hama K, Dohmae N, Takio K, Yamori T, Mills GB, Inoue K, Aoki J and Arai H: Autotaxin has lysophospholipase D activity leading to tumor cell growth and motility by lysophosphatidic acid production. J Cell Biol 158: 227-233, 2002.

10. Tanaka M, Okudaira S, Kishi Y, Ohkawa R, Iseki S, Ota M, Noji S, Yatomi Y, Aoki J and Arai H: Autotaxin stabilizes blood vessels and is required for embryonic vasculature by producing lysophosphatidic acid. J Biol Chem 281: 25822-25830, 2006.

11. Yanagida $\mathrm{K}$ and Ishii S: Non-Edg family LPA receptors: the cutting edge of LPA research. J Biochem 150: 223-232, 2011.

12. Choi JW, Herr DR, Noguchi K, Yung YC, Lee CW, Mutoh T, Lin ME, Teo ST, Park KE, Mosley AN and Chun J: LPA receptors: subtypes and biological actions. Annu Rev Pharmacol Toxicol 50: 157-186, 2010.

13. Meyer Zu Heringdorf D and Jakobs KH: Lysophospholipid receptors: signalling, pharmacology and regulation by lysophospholipid metabolism. Biochim Biophys Acta 1768: 923-940, 2007.

14. Noguchi K, Ishii S and Shimizu T: Identification of p2y9/GPR23 as a novel G protein-coupled receptor for lysophosphatidic acid, structurally distant from the Edg family. J Biol Chem 278: 25600-25606, 2003.

15. Lee CW, Rivera R, Dubin AE and Chun J: LPA(4)/GPR23 is a lysophosphatidic acid (LPA) receptor utilizing $G(\mathrm{~s})-, \mathrm{G}(\mathrm{q}) / \mathrm{G}(\mathrm{i})$ mediated calcium signaling and $\mathrm{G}(12 / 13)$-mediated Rho activation. J Biol Chem 282: 4310-4317, 2007.

16. Yanagida K, Ishii S, Hamano F, Noguchi K and Shimizu T: LPA4/ p2y9/GPR23 mediates rho-dependent morphological changes in a rat neuronal cell line. J Biol Chem 282: 5814-5824, 2007.

17. Lee Z, Cheng CT, Zhang H, Subler MA, Wu J, Mukherjee A, Windle JJ, Chen CK and Fang X: Role of LPA4/p2y9/GPR23 in negative regulation of cell motility. Mol Biol Cell 19: 5435-5445, 2008.

18. Liu YB, Kharode Y, Bodine PV, Yaworsky PJ, Robinson JA and Billiard J: LPA induces osteoblast differentiation through interplay of two receptors: LPA1 and LPA4. J Cell Biochem 109: 794-800, 2010.

19. Gschwind A, Prenzel N and Ullrich A: Lysophosphatidic acidinduced squamous cell carcinoma cell proliferation and motility involves epidermal growth factor receptor signal transactivation. Cancer Res 62: 6329-6336, 2002.

20. Suzuki Y, Ozawa Y, Murakami K and Miyazaki H: Lysophosphatidic acid inhibits epidermal-growth-factor-induced Stat1 signaling in human epidermoid carcinoma A431 cells. Biochem Biophys Res Commun 240: 856-861, 1997.

21. Rolin J and Maghazachi AA: Effects of lysophospholipids on tumor microenvironment. Cancer Microenviron 4: 393-403, 2011.

22. Toyozumi Y, Arima N, Izumaru S, Kato S, Morimatsu M and Nakashima T: Loss of caspase-8 activation pathway is a possible mechanism for CDDP resistance in human laryngeal squamous cell carcinoma, HEp-2 cells. Int J Oncol 25: 721-728, 2004.

23. Weichselbaum RR, Dahlberg W, Beckett M, Karrison T, Miller D, Clark J and Ervin TJ: Radiation-resistant and repair-proficient human tumor cells may be associated with radiotherapy failure in head- and neck-cancer patients. Proc Natl Acad Sci USA 83: 2684-2688, 1986.

24. Msaki A, Sánchez AM, Koh LF, Barré B, Rocha S, Perkins ND and Johnson RF: The role of RelA (p65) threonine 505 phosphorylation in the regulation of cell growth, survival and migration. Mol Biol Cell 22: 3032-3040, 2011.

25. Uehata M, Ishizaki T, Satoh H, Ono T, Kawahara T, Morishita T, Tamakawa $\mathrm{H}$, Yamagami $\mathrm{K}$, Inui $J$, Maekawa $M$ and Narumiya S: Calcium sensitization of smooth muscle mediated by a Rho-associated protein kinase in hypertension. Nature 389: 990-994, 1997.

26. Lee CW, Rivera R, Gardell S, Dubin AE and Chun J: GPR92 as a new G12/13- and Gq-coupled lysophosphatidic acid receptor that increases cAMP, LPA5. J Biol Chem 281: 23589-23597, 2006.

27. Yanagida K, Masago K, Nakanishi H, Kihara Y, Hamano F, Tajima Y, Taguchi R, Shimizu T and Ishii S: Identification and characterization of a novel lysophosphatidic acid receptor, p2y5/ LPA6. J Biol Chem 284: 17731-17741, 2009.

28. Bhave SL, Teknos TN and Pan Q: Molecular parameters of head and neck cancer metastasis. Crit Rev Eukaryot Gene Expr 21: 143-153, 2011. 
29. Hall A: Rho GTPases and the control of cell behaviour. Biochem Soc Trans 33: 891-895, 2005.

30. Routhier A, Astuccio M, Lahey D, Monfredo N, Johnson A, Callahan W, Partington A, Fellows K, Ouellette L, Zhidro S, Goodrow C, Smith A, Sullivan K, Simone P, Le L, Vezuli B, Zohni M, West E, Gleason D and Bryan B: Pharmacological inhibition of Rho-kinase signaling with Y-27632 blocks melanoma tumor growth. Oncol Rep 23: 861-867, 2010

31. Moore KA, Sethi R, Doanes AM, Johnson TM, Pracyk JB, Kirby M, Irani K, Goldschmidt-Clermont PJ and Finkel T: $\mathrm{Racl}$ is required for cell proliferation and $\mathrm{G} 2 / \mathrm{M}$ progression. Biochem J 326: 17-20, 1997.

32. Mack NA, Whalley HJ, Castillo-Lluva S and Malliri A: The diverse roles of Rac signaling in tumorigenesis. Cell Cycle 10 1571-1581, 2011.

33. Shoval I and Kalcheim C: Antagonistic activities of Rho and Rac GTPases underlie the transition from neural crest delamination to migration. Dev Dyn 241: 1155-1168, 2012.

34. Guilluy C, Garcia-Mata R and Burridge K: Rho protein crosstalk: another social network? Trends Cell Biol 21: 718-726, 2011.

35. Kramer RH, Shen X and Zhou H: Tumor cell invasion and survival in head and neck cancer. Cancer Metastasis Rev 24: $35-45,2005$

36. Abraham MT, Kuriakose MA, Sacks PG, Yee H, Chiriboga L, Bearer EL and Delacure MD: Motility-related proteins as markers for head and neck squamous cell cancer. Laryngoscope 111: 1285-1289, 2001.
37. Abe M, Sogabe Y, Syuto T, Yokoyama Y and Ishikawa O: Evidence that PI3K, Rac, Rho and Rho kinase are involved in basic fibroblast growth factor-stimulated fibroblast-collagen matrix contraction. J Cell Biochem 102: 1290-1299, 2007.

38. Harper K, Arsenault D, Boulay-Jean S, Lauzier A, Lucien F and Dubois CM: Autotaxin promotes cancer invasion via the lysophosphatidic acid receptor 4: participation of the cyclic AMP/ $\mathrm{EPAC} / \mathrm{Racl}$ signaling pathway in invadopodia formation. Cancer Res 70: 4634-4643, 2010.

39. Zhang C, Baker DL, Yasuda S, Makarova N, Balazs L, Johnson LR, Marathe GK, McIntyre TM, Xu Y, Prestwich GD, Byun HS, Bittman R and Tigyi G: Lysophosphatidic acid induces neointima formation through PPARgamma activation. J Exp Med 199: 763-774, 2004.

40. Liliom K, Tsukahara T, Tsukahara R, Zelman-Femiak M, Swiezewska and Tigyi G: Farnesyl phosphates are endogenous ligands of lysophosphatidic acid receptors: inhibition of LPA GPCR and activation of PPARs. Biochim Biophys Acta 1761: 1506-1514, 2006.

41. Tsukahara T: The role of PPAR $\gamma$ in the transcriptional control by agonists and antagonists. PPAR Res 2012: 362361, 2012.

42. Rodway HA, Hunt AN, Kohler JA, Postle AD and Lillycrop KA: Lysophosphatidic acid attenuates the cytotoxic effects and degree of peroxisome proliferator-activated receptor gamma activation induced by 15 -deoxyDelta12,14-prostaglandin $\mathrm{J} 2$ in neuroblastoma cells. Biochem J 382: 83-91, 2004. 